\title{
Multi-perspectives crowdsourcing ecosystem in Malaysia
}

\author{
Norjansalika Janom ${ }^{1}$, Raja Nurul Azhani ${ }^{2}$, Syaripah Ruzaini Syed Aris ${ }^{3}$, \\ Nor Shahniza Kamal Bashah ${ }^{4}$, Noor Habibah Arshad ${ }^{5}$, Muhammad Hakim Nadir ${ }^{6}$ \\ 1,2,3,4,5 Faculty of Computer and Mathematical Sciences, Universiti Teknologi Mara, Malaysia \\ ${ }^{6}$ Jouska Enterprise, Malaysia
}

\section{Article Info \\ Article history: \\ Received Nov 22, 2019 \\ Revised Jan 17, 2020 \\ Accepted Feb 4, 2020}

\section{Keywords:}

Analytical hierarchy process

Crowdsourcing

Ecosystem

Multi-perspectives

Weightage

\begin{abstract}
Crowdsourcing has been known as developing industry that able to be used as a platform to get more income and provide opportunity for busineses to conduct their operation in more innovative ways. Crowdsourcing has become an effective way for the companies to offer work opportunity for crowd outside organization to apply their abilities and skills, and receive more money. Under the Malaysian government initiatives called Digital economy, various crowdsourcing efforts and programs have been introduced to catch up with the global development. The ecosystem of crowdsourcing which consists of job provider, platform, micro worker and industry is considered still in a formative stage. Thus, the integration of all these components is not fully discovered and understood yet which, can cause confusion among the crowdsourcing industry players. In order to understand the complex integration of multi perspective micro sourcing ecosystem, the components and its significance priority level need to be identified. In this study, the components that involved in crowdsourcing ecosystem were identified and ranked using analytical hierarchy process (AHP) method. The results can be later used by crowdsourcing industry players to plan more proper crowd sourcing strategic development in Malaysia
\end{abstract}

Copyright $\odot 2020$ Institute of Advanced Engineering and Science. All rights reserved.

\section{Corresponding Author:}

Norjansalika Janom,

Faculty of Computer and Mathematical Sciences,

Universiti Teknologi MARA,

Shah Alam, Selangor, Malaysia.

Email: norjan@fskm.edu.my

\section{INTRODUCTION}

Crowdsourcing has been known as new way for the companies to provide opportunity for people outside the organization to apply their expertise and use their time wisely by earn more income through crowdsourcing platform [1]. Crowdsourcing takes places from the buyer of small source project or partial task from a spread and split global workforce of small provider. Usually, crowdsourcing involve big task which is broken down into micro tasks [1,2]. Through crowdsourcing platform and its intelligent engine, the task will be distributed to the registered crowd workers for them to complete the tasks through their problem solving skills, expertise or innovate ideas. The advantage of crowd sourcing is usable for the persons on the internet through open call which anybody in the network can join.

Internationally, crowdsourcing industry recorded rapid economic growth in the recent years. According to [3] in 2011, the industry have grown exponentially to 291.8 million compared to only 400,000 in 2008. In 2010, the total revenue of crowdsourcing industry's also has approximately grew to $52.6 \%$. The grew continually accelerated further by $7 \%$ in 2011 [3]. The international management team has decades of experience in the crowd sourcing. Furthermore, North America and Europe were known as the largest job providers in the global crowdsourcing industry which collectively offered $90 \%$ of crowdsourcing job [3]. 
In Malaysia, crowdsourcing has been recognized as new industry that able to uplift the and bring significant benefits to business and people in general. Eventhough the crowdsourcing phenomenon is considered as faily new and still at infancy stage, there is positive predictions and indications of its development. Under initives by government link company, Malaysia Digital Eocomy Corporation (MDEC), various crowdsourcing efforts and programs have been planned and implemented. eRezeki, was one of the programs which intendeded to provide alternative online channel for people to generate income by working as crowd worker [3]. The project targeted all levels of society especially the poor or under privillged community. The eREZEKI platform has been launched by the Malaysian government that enables the crowds in Malaysia to involve in crowdsourcing. With the launching of eREZEKI it was believed that the project be able to encourage more Malaysians to participate in crowdsourcing.

However, in order to success, crowdsourcing initiatives need to carefully plan. Crowdsourcing ecosystem involves high degrees of difficulty and complexity of multiple relationships and interactions between organizations, platform providers, crowd workers and government $[2,4]$. These components have their own roles, principles, concepts, values and practices. Thus, extensive studies of multi-perspectives of crowdsourcing ecosystem components are critically needed. The identification of multi perspectives crowdsourcing ecosystem, the components and its significance priority level through Analytical Hierarachical Processing (AHP) method can help to develop further understanding on how crowdsourcing really work, how it create value and how to prioritize.

\section{RESEARCH BACKGROUND}

Crowdsourcing has become a new society paradigm that might change the outsourcing landscape in the future [2]. Crowdsourcing has been argued as "the biggest paradigm shift in innovation since the Industrial Revolution" [4]. According to Arshad et al [5], in order to ensure the effectiveness of the micro sourcing projects in Malaysia, it is required a complete ecosystem that will allow the components to link with one another. In crowdsourcing, there are currently three main components of ecosystem which are job provider, platform and crowd worker. Based on Hassan et al [6], job provider will outsource the tasks to micro sourcing platform. Job provider is the person that responsible to provide the tasks. The examples of job provider are the organization from public sector, Small Medium Enterprise (SME), International and the listed company. They will be ordered to do the tasks and send to the platform to do the next step for the task. Platform is a very important component in micro sourcing ecosystem to make a connection between job provider and micro worker [4]. Crowdsourcing provides a platform for new element to form perfect connections (exercising autonomy and creativity). Over the past decade, many platforms have been developed by many companies. In Malaysia, currently there are only four crowdsourcing platforms operated by four different companies which are Human Capital Connection Sdn. Bhd, Multimedia Synergy Corporation Sdn. Bhd, Ikrar Potensi Sdn. Bhd and also Pernec Corporation Berhad. Even though Malaysia has its own platform but the functions are very limited [4]. Most of the crowdsourcing platforms in Malaysia acts as the job matching between micro worker and tasks. Only recently, the launching of new platform called eREZEKI has a similar functionalities with the existence international crowdsourcing platforms.

Multi perspectives crowdsourcing dynamic ecosystem model deals with the process of understanding the relevant business domain (usually relatively stable), business processes (usually more volatile), and information technology and stakeholders interaction [5]. Micro worker is another crowdsourcing ecosystem who are responsible to complete the task from the platform. The task is open market and can be done by anyone. Micro worker will get a different income depends on the type of task, number of hours and performance of the task. Micro workers can complete their tasks by doing through online or offline. In completing the tasks, micro workers have been given more flexibility in choosing their own working time, locations and duration based on the nature of task provided in the platform.

However, to manage an effective crowdsourcing ecosystem, it do not not only involves Job Providers, Crowd Workers and Platforms but also the enablers [6-9]. The policies, incentives, vision and strategy, governance, business process management, infrastructure, human capital, education and external environment are among the significance enablers that might influence the crowdsourcing ecosystems. Thus, the widely used of crowdsourcing has changed the landscape of local and global business ecosystem model through various integrations of goals of businesses or organizations, structure, processes, activities, resources, information, people and behaviour. Respectively, the crowdsourcing ecosystem model must be able to represent the effective and efficient integration of these various components. Therefore this research views the emergence of crowdsourcing ecosystem as a paradigm shift that will fundamentally go beyond the economical, social, ecological, technological developments and business operation. The integration and relationship interactions between crowdsourcing components of micro workers, organization or job providers, platforms and various external factors are crucial in determining the success of crowdsourcing projects. 


\section{METHODOLOGY}

As been mentioned earlier, each component might have different significance levels which require crowdsourcing players to focus and prioritize the most critical and the least critical components. Thus, to effectively identify the weightage of each component, Analytical Hierarachical Processing (AHP) method was used. The scoring and the weightage techniques of AHP can help to choose the critical criteria that need to be prioritized in setting up the crowdsourcing ecosystem. There are many similar existing researches that use scoring system to assits decision making [9-11]. The AHP applies the quantitative and qualitative methods through interview sessions with subject matter experts. Expert evaluations were used to ensure the completeness, the validity and the weightage of the crowdsourcing multi perspectives components. The subject matter experts provided feedback in relevance to the significance and weightage of each sub criteria under crowdsourcing ecosystem. The selection of the experts was based on three criteria such as: (1) have been involved in the planning, implementation and development of platform and the crowdsourcing project as a whole. (2) knowledgeable and have experience related to crowdsourcing industry in Malaysia (3) willingness to involve in the research.

Based on these criteria, five management executives from five different organizations were selected and interviewed. The management executives included CEO, Project Directors and senior management.

a) Expert 1 was the Director of the Crowd Business Innovation Centre, UiTM. The objective of the centre is to serve as a centre for research, consultation, training and as one stop information center. The centre focuses on the innovation in the production of high-impact ideas related to crowdsourcing. It also focuses on human development and training for each component involved in crowdsourcing industry. She was responsible to lead the planning, development and maintenance of the centre.

b) Expert 2 was senior consultant from the Crowd Business Innovation Centre, UiTM. The expert has more than 3 years experience working in crowdsourcing project. One of the projects involved the collaboration with Malaysia Development Economy Corporation (MDEC) to develop National Microsourcing Strategics for Malaysia. He has been responsible to lead the planning, implementation, management, monitoring and maintenance of the project since the early initiatives in 2012.

c) Expert 3 was the Senior Manager of MDEC. He was one of the lead persons that champion the implementation of government crowdsourcing initiaves eERezeki program in Malaysia. The eRezeki program enables citizens, especially low-income groups, generate additional income by doing digital assignments via online crowdsourcing platform.

d) Expert 4 was the Chief Executive Officer of the SmartJobs \& Services Sdn Bhd. The expert was responsible to train fresh graduates and anybody that interested to do microsourcing freelance jobs. He has wide experience related to the usage and application of various national and international crowdsourcing freelance platforms.

e) Expert 5 was the Managing Director of Human Capital Connection Sdn Bhd. The company has been involved as one of the industry players to develop crowdsourcing platform for Malaysia market. The company was one of the main developer nd main suppliers for crowdsourcing task through ERezeki platform. The expert also has been continuously plays a key role in promoting and motivating the micro workers to get involve and participate in online crowdsourcing platform.

The selection of experts from specific backgrounds as mentioned above is categorized under focus group approach. According to the focus group research approach, the total respondents participating in this type of research are generally small. Brown [12] and Zakaria and Janom [4], said that the group should consist of 4-12 if the group is homogeneous and 6-12 if heterogeneous. Thus, since the research is focused on crowdsourcing in ICT related industry, the five experts employed in this research is within the acceptable range of focus group standard. This research approach is categorized under descriptive quantitative techniques since it cannot provide a robust measure of reliability particularly in the investigation of small populations of expert opinions. Next section discusses about the AHP method that been used to identify the priority and significance weightage for each factor under each ecosystem component.

\section{FORMULATING PRIORITY AND WEIGTAGE USING AHP}

As mentioned in previous section, the AHP was used to identify specific weight for each criteria. AHP is a suitable method to set priorities and weights which involve qualitative and quantitative aspects of a decision. AHP is another method used in determining weightage over multiple selection of given alternatives and prioritising. AHP was originally developed by Saaty in 1980 and has been used widely as decision aiding techniques. The method outweighs other methods especially to make decision making choices easier related to scarce resources allocation and others $[13,14]$. AHP method can be an excellent point for researcher to do prioritization between few alternative of choices. Due to its structured method technique, AHP has been used effectively to elicit biased opinions of decision makers in weighting and prioritization. The methods also are 
reliable, repeatable and can easily be incorporated into multiple, objective programming formulations [15]. This makes it applicable to aid the decision making process from simple personal decisions to the complex decisions in various fields of sports, politics, finance, economics, management science, science and politics. management science, economics, finance, politics, and sports [16]. Most in the researches, it shows how AHP has been used widely used to assist decision making process in determining the best selection alternatives in various researches for example the identification of critical factors in risk management [17], development of road safety index [13], identification of healthcare compatibility [18], determination of individual data analtics [19], landslide vulnerability [20] and many others.

The process of constructing crowdsourcing ecosystem criteria weightage will involve several phases of multi-criteria decision making process. In each phase, the researcher applies methodological choices that quantify the weights of each ecosystem component rankings. As there is limited method for developing composite criteria, several techniques for criteria selection, weighting and aggregation need to be considered. As mentioned earlier, AHP includes both the rating and comparison methods of two or more criteria. AHP begins with weighting the factors through hierarchical structure of the criteria for each ecosystem.

\subsection{Weighting the factors}

It is important to define the decision problem clearly since it The decision problem should be defined clearly since it leads the whole research process. In this research, in determining the key criteria of crowdsourcing ecosystem components, AHP was used to evaluate each factor. The factors were arranged in a proper hierarchy classification of different levels constituting goal, criteria and sub-criteria. Overall there are one goal, 4 criterias and 14 sub criterias as shown in Figure 1. These classification were based on research model adopted from Sharma [21], Hirth and HoBfeld [22] and Zakaria et al [4].

a) The micro sourcing ecosystem model consists of four main criteria, which each criteria has different sub criteria based on the defined definitions below:

b) Job provider can be organization or people who provide tasks and jobs through the platform. It can be government agency, businesses, professional services or even individual who open the opportunity for online works to the crowd. It also can be defined as an organization that outsources the tasks to the platforms and distributes it to the micro workers and pays them accordingly.

c) Platform is a vital part as it provides channel for the job provider and micro worker to distribute and share tasks online. The platform should provide connection between job provider and micro worker.

d) Micro worker is the crowd that are responsible in completing the task given. Micro worker is defined as the pool of labor force that have specific skills to complete various tasks that been offered online. The worker who will complete the task given by the job provider. Usually a micro worker will be asessed thorugh specific assessment to determine whether they can do the work and get paid for that.

e) Industry consists of external governance and external environment which help to promote success of microsourcing based on the international micro sourcing players and the experienced micro workers. The wide involvement of crowd workers can encourage different talents and skills to participate. The governance structure might focus on the linkages and trust among within and outside platform.

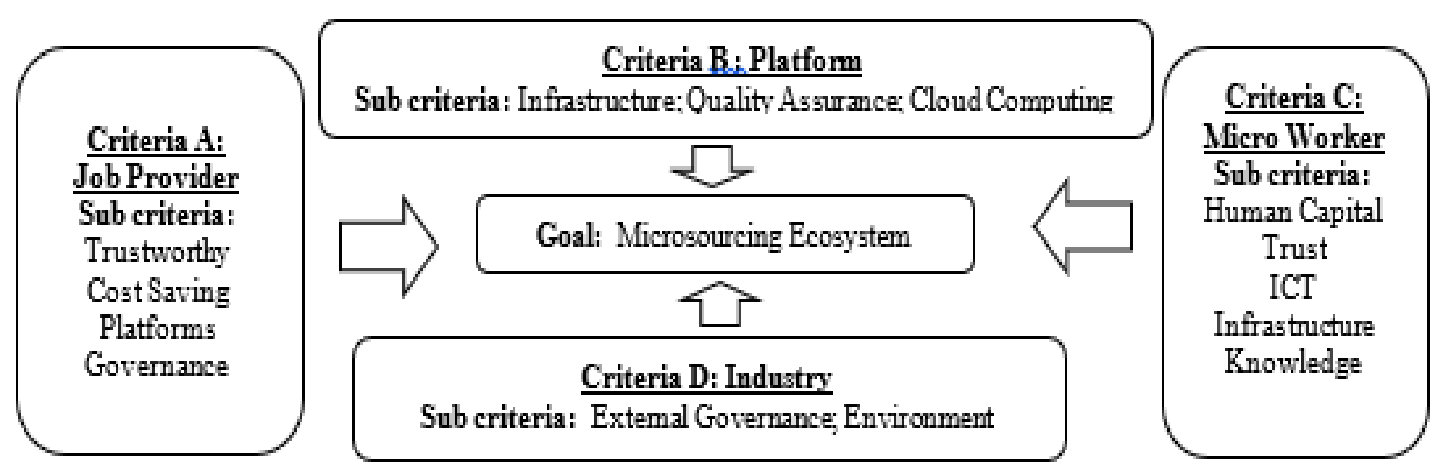

Figure 1. Research model adopted from Sharma [21], Hirth \& HoBfeld [22] and Zakaria et al [4]

\subsection{Data collection from experts to determine the weightage of each criteria and sub criteria}

In order to determine the weightage and ranking of each factor, questions were developed based on model as shown in Figure 1. All experts were given the list of all the criteria and sub criteria of 
crowdsourcing ecosystems in the form of questionnaire. Experts were asked to identify the significance, as well as the weightage and the degree of criticality of each. Due to their expertise, experts able to provide reviews which can be used to determine the reliability and validity of the multi perspectives crowdsourcing ecosystem criteria. Data were collected through feedback from the five experts mentioned. The experts rated the relative important within each criteria based on the scale of 1 which was equal importance to 9 which was absolute importance. After all criteria have been compared, a paired comparison or judgment matrix is formed.

\subsection{Employing the pair-wise comparisons}

The criteria and sub criteria in the decision hierarchy were rated using the pair-wise comparison. A pairwise comparison matrix was formed to show their relative importance to one another. In order to estimate the relative weights of sub criteria, the sub criteria was compared in couples, the weight of each element was computed through a through a number of numerical calculations. The "Eigenvalue" approach was used to estimate the relative weight of decision criteria and aggregate the relative value of decision elements to come out with priority list of alternatives. The total relative value for each sub criteria group will be 1 .

\subsection{Calculating the degree of consistency in order to validate the results}

In order to identify if there were any inconsistency of feedbacks collected from experts, it is important to calculate the consistency ratio of the estimated matrix vector. Consistency ratio (CR) through the pair-wise comparison calculation was used to calculate the consistency ratio. Saaty [23, 24] has set the acceptable consistency ratio index (CRI) for different matrices' sizes based on below:

1) the $\mathrm{CR}$ value is 0.05 for a 3 -by-3 matrix;

2) 0.08 for a 4-by-4 matrix; and

3) 0.1 for larger matrices. are valid.

If the consistency level falls into the acceptable range as mentioned above, the weight results

\section{FINDINGS}

Based on the AHP methodology, final weight as represent in Table 1 to Table 4 show the final relative importance of each sub criteria, the more important the factors, the greater the final weight will be. $\mathrm{CR}$ values are also shown to have acceptable consistency. The consistency is measured by consistency ratio using own calculations random index (RI). The results of participants who answered consistently were included in the analyses as been shown in Table 1-Table 4. All crowdsourcing ecosystem criteria of job provider, platform, micro worker and industry, have perfect CR of 0.00 which means that all the experts have given consistent feebdback throughout the questionnaire.

From the job provider perspectives as shown in Table 1, the trustworthy, cost saving, platform, governance and micro worker seem to be an important crowdsourcing ecosystems. Both factors related to cost saving were equally important while the other factors under platform, governance and micro worker also been given specific weightage. Since crowdsourcing task online using the anonymity concept, the trustworthy, reliable platform combine with proper governance and clear instruction provided to micro worker can ensure the success of crowdsourcing. Finally, the priorities of individual participants were aggregated to analyze the priorities of all the participants.

As shown in Table 2, all factors under network infrastructure, quality assurance, cloud computing have been evaluated equally. Reliable network infrastructure will allow sharing of data between tasks and platforms. Each factor was scored $0.34,0.33$ ad 0.33 relatively. It is also important for platform to have intelligent engine in order to check the quality of submitted tasks before send it back to job provider. The usage of cloud computing technology also able to provide flexibility, lower cost and improve scalability for platform providers. The weightage scores able to guide the crowdsourcing platform to which factors can be strategically prioritized in ensuring the success of crowdsourcing implementation.

Table 3 shows the weightage of sub criteria related to micro worker. Under human capital, sufficient knowledge and skills have been weigtaged as the critically important with 0.61 relative score, compared to the time given to workers to complete tasks which only score 0.39 . The other factors under trust, ICT infrastructure and knowledge have shown about the same relative importance weightage.

As mentioned ealier, the total weightage for each sub criteria group is equivalent to 1 , thus as shown in Table 4, for external governance, three factors relatively score about the same weightage of 0.26 and one factor scores 0.22 . However, for external environment, reliable and trusted local industry got the highest score of 0.36 followed by cultural enerprenuership with 0.33 and wide involvolvement of crowd worker with 0.31 . 
Table 1. Final weight and CR for job provider criteria

\begin{tabular}{|c|c|c|c|}
\hline $\begin{array}{l}\text { No } \\
\text { A1 }\end{array}$ & $\begin{array}{l}\text { Criteria A: Job Provider } \\
\text { Sub criteria: Trustworthy }\end{array}$ & Weightage & CRI \\
\hline 1 & Trust and security to establish crowdsourcing & 0.27 & 0.00 \\
\hline 2 & Good linkage and trust to ensure platform security & 0.27 & \\
\hline 3 & Capability anonymous crowd to do jobs online & 0.22 & \\
\hline 4 & Crowdsourcing emphasize data security and confidential policies & 0.24 & \\
\hline $\mathrm{A} 2$ & Sub criteria: Cost saving & & \\
\hline 5 & Crowdsourcing as a way to lower operation costs & 0.50 & 0.00 \\
\hline 6 & Crowdsourcing reducecost related to labour & 0.50 & \\
\hline A3 & Sub criteria: Platform & & \\
\hline 7 & Platform to have their own niche and focus area & 0.38 & 0.00 \\
\hline 8 & Platform is needed complete tasks in more efficienct way & 0.29 & \\
\hline 9 & Platform helps the job provider to advertise the jobs & 0.34 & \\
\hline A4 & Sub criteria: Governance & & \\
\hline 10 & Company identify appropriate strategies and guidelines & 0.49 & 0.00 \\
\hline 11 & The tasks compatible with current business practices and cultural norms & 0.51 & \\
\hline A5 & Sub criteria: Micro worker & & \\
\hline 12 & Clear instructions are provided to micro workers & 0.52 & 0.00 \\
\hline 13 & Micro workers who against instructions and criteria should be blacklisted & 0.48 & \\
\hline
\end{tabular}

Table 2. Final weight and CR for platform criteria

\begin{tabular}{|c|c|c|c|}
\hline No & Criteria B: Platform & Weightage & CRI \\
\hline B1 & Sub criteria: Network Infrastructure & & \\
\hline 14 & Reliable network infrastructure allow jobs to distribute faster & 0.34 & 0.00 \\
\hline 15 & Public wireless internet access points allow tasks completed fasters & 0.33 & \\
\hline 16 & Existing infrastructure should be leveraged and utilised & 0.33 & \\
\hline $\mathrm{B} 2$ & Sub criteria: Quality Assurance & & \\
\hline 16 & Completed tasks need to go through quality assessment & 0.35 & 0.00 \\
\hline 17 & Platform with quality assurance emphasize on good response time, quality work and privacy data & 0.33 & \\
\hline 18 & The standard requirement can be achieved through quality assurance & 0.32 & \\
\hline B3 & Sub criteria: Cloud Computing & & \\
\hline 19 & $\begin{array}{l}\text { Platform use cloud computing to leverage various enterprise-level applications provided by many ICT } \\
\text { companies }\end{array}$ & 0.34 & 0.00 \\
\hline 20 & Cloud computing allow transfer of information and functionality & 0.33 & \\
\hline 21 & Cloud computing distributed server allow flexible applications & 0.33 & \\
\hline
\end{tabular}

Table 3. Final weight and CR for micro worker criteria

\begin{tabular}{|c|c|c|c|}
\hline No & Criteria C: Micro Worker & Weightage & CRI \\
\hline $\mathrm{C} 1$ & Sub criteria: Human Capital & & \\
\hline 22 & Sufficient technical and specialized skills to complete tasks & 0.61 & 0.00 \\
\hline 23 & Ample time given to micro worker to complete tasks & 0.39 & \\
\hline $\mathrm{C} 2$ & Sub criteria: Trust & & \\
\hline 24 & Linkage and trust between worker and platform promote security & 0.52 & 0.00 \\
\hline 25 & Agreement/contract protect the micro worker from any kind of fraud. & 0.48 & \\
\hline $\mathrm{C} 3$ & Sub criteria: ICT Infrastrucure & & \\
\hline 26 & Cloud-based applications make it easier to access platforms & 0.27 & 0.00 \\
\hline 27 & Adoption of mobile phone, computer, internet and other help micro worker to complete the tasks. & 0.27 & \\
\hline 28 & Easy access into the internet improve micro worker performance & 0.22 & \\
\hline 29 & High internet bandwidth helps to complete and submit tasks faster. & 0.25 & \\
\hline $\mathrm{C} 4$ & Sub criteria: Knowledge & & \\
\hline 30 & Micro worker need to have technology knowledge & 0.53 & 0.00 \\
\hline 31 & Micro worker can choose tasks based on their interests & 0.47 & \\
\hline
\end{tabular}

Table 4. Final Weight and CR for industry criteria

\begin{tabular}{|c|c|c|c|}
\hline No & Criteria D: Industry & Weightage & CRI \\
\hline D1 & Sub criteria: External governance & & \\
\hline 32 & Proper government support to adopt crowdsourcing & 0.22 & 0.00 \\
\hline 33 & Crowdsourcing governance committee to oversea the development and maintenance & 0.26 & \\
\hline 34 & Specific crowdsourcing rules, regulatory and policies & 0.26 & \\
\hline 35 & Diverse population with multicultural background able to attract international firms crowdsource their tasks & 0.26 & \\
\hline $\mathrm{D} 2$ & Sub criteria: External Environment & & \\
\hline 36 & Reliable and trusted local crowd sourcing champions are needed & 0.36 & 0.00 \\
\hline 37 & Economic environment that promotes culture of enterprenuership & 0.33 & \\
\hline 38 & Wide involvement of crowd workers with different skills and talents & 0.31 & \\
\hline
\end{tabular}




\section{CONCLUSION}

In conclusion, this research has gathered all the ecosystem components from various perspectives, of different criteria and sub criteria groups. In order to ensure the effectiveness of crowdsourcing in Malaysia, it is required a complete ecosystem that will integrate the ecosystem components with one another. The judgment scales from experts through AHP method was used to identify weightage of each factor. Based on the results, some of the factors under job provider, platform, micro worker and industry ecosystems are mostly equal important with consistency index of 0.00 . Knowing the weightage of each factor can help to prioritize factors based on the level of importance. The results also can guide towards the effective strategics of crowdsourcing industry growth development. All crowdsourcing players need to understand the relationhips and the importance of those components that build up the crowdsourcing digital economy. From the results it can be clarified which ecosystem is more important for the industry players to focus on.

\section{ACKNOWLEDGEMENTS}

The authors would like to thank to Research Management Institute, Universiti Teknologi MARA, for their funding support under LESTARI Grant with project code 600-IRMI/DANA 5/3/LESTARI (0136/2016).

\section{REFERENCES}

[1] H. Ikediego, et al., "Crowd-sourcing (who, why and what)," International Journal of Crowd Science, vol. 2, no. 1, pp. 27-41, 2018.

[2] N. Zakaria, et al., "Assessment of crowdsourcing task multidimensional relationship model through application prototype," Indonesian Journal of Electrical Engineering and Computer Science, vol. 12, no 1, pp. 378-385, 2018.

[3] Massolution, Crowdsourcing LLC, "Crowdfunding Market Outlook Report," 2013.

[4] Z. Zakaria, N. Janom, and N. H. Arshad, "Low income community as crowd worker for crowdsourcing: Issues, challenges and future direction," International Journal of Engineering \& Technology, vol. 7, no. 4.33, pp. 65-70, 2018.

[5] N. H. Arshad, et al., "Micro sourcing strategic framework for low income group," International Journal of Advanced Computer Science and Applications, vol. 4, no. 6, pp. 97-105, 2013.

[6] Hassan, S. R. et al., "Conceptual model for a sustainable crowdsourcing ecosystem," Pertanika Journal Science and Technology, vol. 25, pp 89-98, 2017.

[7] I. Christensen and C. Karlsson, "Open innovation and the effects of crowdsourcing in a pharma ecosystem," Journal of Innovation \& Knowledge, vol. 4, no. 4, pp. 240-247, 2019.

[8] A. Gervald, "HRM systems and implementation within crowdsourcing platform ecosystem," University of Twente, 2019.

[9] M. Bazzi and H. Chamlal, "Intelligent credit scoring system using knowledge management," International Journal of Artificial Intelligence, vol. 8, no. 4, pp. 391-398, 2019.

[10] T. B. Rebelo, et al., "Prioritising species of special concern for monitoring in table mountain national park: The challenge of a species-rich, threateded ecosystem," International Journal of Artificial Intelligence, vol. 53, no. 2, pp. 158-171, 2011.

[11] S. Selvaraju and T. V. Geetha, "Ranking and evaluation of automatically constructed semantic search paths," International Journal of Artificial Intelligence, electronic only, pp. 133-148, 2008.

[12] J. B. Brown, "The use of focus groups in clinical research," Crabtree, B. F., \& Miller, William L (eds.). Doing qualitative research, Thousand Oaks: Sage, pp. 109-124, 1999.

[13] E. Hermans, F. V. D. Bossche, and G. Wets, "Uncertainty asssessment of the road safety index," Reliability Engineering and System Safety, vol. 94, no, 7, pp. 1220-1228, 2008.

[14] M. S. D. Putra, S. Andrayana, Fauziah, and A. Gunaryati, "Fuzzy analytical hierarchy process method to determine the quality of gemstone," Advances in Fuzzy Systems, vol. 2018, 2018.

[15] N. S. Md Zaini, et al., "Selecting the best composting technology using analytical hierarchy process (AHP)," Jurnal Teknologi, vol. 77, no. 1, pp. 1-8, 2015.

[16] N.I.S. Sulaiman, et al., "Analytical hierarchy process and markov chain in shared knowledge through social media," Jurnal Teknologi, vol. 77, no. 5, pp. 57-61, 2015.

[17] P. Z. Razi, M. I. Ali and N. I Ramli, "Overview of analytical hierarchy process decision making method for construction risk management," IOP Conference Series: Earth and Environmental Science, no. 244, 2019.

[18] K. Schmidt, et al., "Applying the analytic hierarchy process in healthcre research: A Systematic literature review and evaluation of reporting," BMC Medical Informatics and Decision Making, vol. 15, no. 112, pp. 1-27, 2015.

[19] D. J. Y. Tey, et al., "A novel neutrosophic data analytic hierarchy process for multi-criteria decision making method: A case study in Kuala Lumpur stock exchange, special section on new trends in brain signal processing and analysis," IEEE Access, vol. 7, pp. 53687- 53697, 2019.

[20] L. Nahayo, et al., "Estimating landslides vulnerability in rwanda using analytic hierarchy process and geographic information system," vol. 15, no. 3, pp. 364-373, 2019.

[21] A. Sharma, "Crowdsourcing critical success factor model strategies to harness the collective intelligence of the crowd," pp. 1-22, 2010.

[22] M. Hirth, T. Hoüfeld, and P. Tran-Gia, "Anatomy of a crowdsourcing platform - using the example of microworkers.com," Fifth Int. Conference on Innovative Mobile and Internet Services in Ubiquitous Computing, 2011.

[23] T. L. Saaty, The Analytic Hierarchy Process. New York: McGraw-Hill, 1980

[24] T. L Saaty, and Vargas L.G. Prediction, Projection and Forecasting. Boston: Kluwer Academic Publishers, 1991. 